This item was submitted to Loughborough's Research Repository by the author.

Items in Figshare are protected by copyright, with all rights reserved, unless otherwise indicated.

\title{
Technologies of memory: practices of remembering in analogue and digital photography
}

PLEASE CITE THE PUBLISHED VERSION

http://dx.doi.org/10.1177/1461444814532062

PUBLISHER

SAGE ( ) The Author(s)

VERSION

AM (Accepted Manuscript)

\section{PUBLISHER STATEMENT}

This work is made available according to the conditions of the Creative Commons Attribution-NonCommercialNoDerivatives 4.0 International (CC BY-NC-ND 4.0) licence. Full details of this licence are available at: https://creativecommons.org/licenses/by-nc-nd/4.0/

\section{LICENCE}

CC BY-NC-ND 4.0

\section{REPOSITORY RECORD}

Keightley, Emily, and Michael Pickering. 2014. "Technologies of Memory: Practices of Remembering in Analogue and Digital Photography”. Loughborough University. https://hdl.handle.net/2134/18046. 


\title{
Technologies of Memory: Practices of Remembering in Analogue and Digital Photography
}

Dr Emily Keightley and Professor Michael Pickering (Forthcoming), New Media and Society

\begin{abstract}
This article demonstrates the need always to consider change against continuity and continuity against change in the analysis of mnemonic technologies. It does so by exploring what has happened in the move from analogue to digital photography, looking in particular at how this has affected the meanings of personal photographs and the practices of remembering associated with them. In contrast with technologically determinist perspectives which have been, however latently, manifest in writing on new media, the value of exploring vernacular photography as a specifically mnemonic practice is that it turns our attention to the ways in which photographic practices are bound up with longerterm social uses and cultural values. Our analysis focuses on changes in four key categories of photographic practice that relate to the analogue/digital shift: photo-taking; photostoring; photo-viewing; photo-sharing - all of which have consequences for the uses of photography as a mnemonic resource. They have all been altered in varying degrees by the advent of digital technologies, but with people continually making comparative evaluations of old and new, drawing on the former as a key aspect of learning how to use the latter.
\end{abstract}

\section{Keywords}

Analogue, digital, photography, memory, visual technology, domestic media, technological change

\section{Introduction}

An abiding temptation in writing about new or recent developments in communications and cultural technologies is to exaggerate the degree of change involved. This guarantees a certain rhetorical force to what is written since it carries an overweening sense of the weight and significance of the change that is being claimed. Such exaggeration implies its own endorsement almost regardless of any questioning of the credentials of the putative change. The effect of loading emphasis onto the newness of technological development is to downplay or disregard how it relates to what precedes it and in some way or another has laid the ground for this development. Stressing change, and in particular arguing that it makes for a major rupture with any antecedents, has the inevitable consequence of making us lose sight of the possible continuities that may be involved, and of how the change itself may entail such continuities.

In this article, we want to demonstrate the need always to consider change against continuity and continuity against change, no matter how dramatic the change or how entrenched the continuity may appear to be. We shall do so by exploring what has happened in the move from analogue to digital photography, looking in particular at how this has affected vernacular photographic practices and the meanings of personal photography. This is a suitable case to choose in illustration of our argument because, while 
the differences in the technologies for taking photos have influenced what people do with their cameras and the images they capture, an important shift in perspective emerges once we move away from an exclusive focus on those technologies and look as well at how they are being used and applied. One of our main reasons for examining their uses and applications is to counter the assumption that technology is inevitably the driving force of social and cultural change. Here we encounter a somewhat paradoxical situation across much of the writing on 'new' media in which lip-service is paid to arguments against technological determinism while sometimes allowing a latent form of such determinism to slide back in and so underlie the ways in which communications technologies are accounted for. This is very much the case with arguments concerning digital photography where the focus is primarily on the technology involved, and analysis is based upon extrapolations from the technology rather than being considered from the perspective of everyday practices and the ways in which digital technology is applied in making images, storing them, retrieving them and integrating them into broader remembering practices. There is an alltoo-easy leap from noting the replacement of the film negative by the binary code on electronic chips to claims that this radically transforms how we think about the photographic image in its relationship to pro-camera reality and henceforward to the past that is represented in the image. This leap has been evident since the 1990s, when the takeup of digital photography began to gain momentum. A particular focus in claims for radical transformation and loss fell on the digital manipulation of 'the real' and depletion of the truth of the photographic image.

For example, as early as 1992, William Mitchell (1992: 8) was arguing that digital imaging 'deconstructs the very ideas of photographic objectivity and closure'. He saw the period associated with analogue photography as an 'interlude of false innocence' in which the photographic image was naively accepted as 'recorded fact': 'Today, as we enter the post-photographic era, we must face once again the ineradicable fragility of our ontological distinctions between the imaginary and the real ...' (ibid: 225). For Mitchell, the ready manipulation and open-endedness of the digital image make clear photography's construction of the visual world and radically call into question the relationship between the photograph and the object or scene it represents. With such manipulation the quality and worth of the photograph as 'true evidence' is seen to diminish sharply because recognition of the difference between real and false is now lost. Alan Trachtenberg argues likewise:

In digital photography memory, potency and reality lose their distinctiveness. In place of a store of images (such as negative versions of positive pictures) are electronic 'chips' that compress electrical charges that can be called up, shaped and reshaped by command as images that look like those of a sensory past though not necessarily so (2008: 114; emphasis in original).

Manipulation is extended even more with Photoshop and similar software enabling the digital enhancement of photographs, from the removal of 'red eye' onwards. Digital manipulation means that 'visual images no longer have any reference to the position of an observer in a "real" optically perceived world' (Crary, 1993: 1). They are no longer 'the result of the momentary and privileged meeting of subject and photographer' because digitalisation enables us to 'reach backward in time, repudiating the photographer's judgement' (Ritchin, 1990: 30-31). To this Geoffrey Bowker adds that our past 'has always been malleable, but now it is malleable with a new viscosity' (Bowker, 2005: 5). 
Such arguments either underplay the history of manipulation and enhancement associated with analogue photography for the sake of contrast with what has succeeded it, or play up the framing, staging and coding of the photograph, along with the viewer's interpretation of it, in claiming that digitalisation has made us radically question the 'truth' of all forms of photographic imagery. The result of both strategies is to set up the analogue photograph in binary opposition to the digital image, with the dangers of manipulation being raised far more sharply by the latter. Obviously these dangers exist, particularly in relation to the visual images used in news journalism, where they are quite rightly a matter of concern. Yet it is precisely here that we need to take care not to elide different photographic practices by making the technology itself our primary consideration, for despite the availability of computer software enabling post-shot interference with the image, such manipulation is much less a case for concern with amateur as opposed to professional photography. There the use and evaluation of digital images remains much closer to the analogue forms which preceded them, suggesting that we need to assess more carefully and in greater detail how the analogue/digital shift is being accommodated across time.

The technologically-driven manner of these arguments is confirmed by the absence of any consideration of the time involved in the embedding of new technologies in everyday life and their assimilation to the diverse and at times alternating imperatives which people follow in recording and remembering the past. The analogue/digital shift in domestic photography is still comparatively recent, and across various social categories people are still coming to terms with it and trying out a number of ways of accommodating to it. In this respect, declarations of entrance into a post-photographic era, and arguments claiming irreversible changes in photographic practice and the meaning of vernacular photography wrought by digital technologies, are, quite simply, premature.These technologies have only been used on a widespread scale for less than two decades. Their relationship to memory and remembering is not yet clear because this is still in the process of emergence. When we turn aside from thinking exclusively in terms of the technology, and look instead at how digital cameras and digital imagery are being adapted to existing patterns of remembering in everyday life, we see that, alongside changes that are being made to these patterns, there are clear signs of continuity in the ways people are adapting them to older modes of storage and retrieval, and older idioms of drawing on and relating to photographs in thinking and talking about the pasts that they share.

In drawing attention to these arguments, we share Sarvas and Frohlic's (2011) concern to question the nature and extent of changes in photographic practices which emerge in the uneven transition from analogue to digital photography. Like them we see this technological transition as a period of ferment in vernacular photography in which both continuities and change can be observed, and in addition, find these patterns of continuity and change occurring in various ways in different domains of photographic practice, from photo-taking to photo-storage. Our argument diverges from theirs in relation the relative importance of memory as the central function of vernacular photographic practice, which we will demonstrate using our fieldwork data. Sarvas and Frohlic suggest that 'communication has surpassed memory as the primary function of photography' (2011: 133) while our analysis aims to demonstrate that the interweaving of photography with everyday practices of remembering is one of the key, indeed perhaps the key site of continuity in the movement between analogue and digital photography. 
In view of this, it is central to our own argument that digital and analogue technologies are seen as relational in terms of their practices of use and the meanings of the texts that are produced by their use. The everyday practices associated with digital photography are in various ways continuous with those developed in relation to analogue photography, even as they are also changing. There is no neat timeline for these adaptations in practice and evaluation since they are being made through their interrelation with previous ways of engaging with the photographic image, especially as it has been used as a vehicle of vernacular remembering. That is why we reject the claim put forward by Mitchell that 'we can identify certain historical moments at which the sudden crystallisation of a new technology ... provides the nucleus for new forms of social and cultural practice' (1992: 20). In exploring changes in vernacular photographic practice and the ways in which meanings and evaluations are made out of mechanically recorded images, no such nucleus is identifiable. There has, as we shall see, been neither a swift nor straightforward move initiated by digital technologies into new forms of practice. Instead, what is revealed is a much more complex mixture of earlier purposes and practices continuing to prevail even as they are being modified by the various conditions and possibilities made available by such technologies.

\section{Methodology}

In order to show how this move is being made, we draw in this article on a large data set we have accumulated concerning the relationship between memory and the personalised use of media technologies. ${ }^{1}$ We recruited 110 participants to take part in one-to-one interviews, self-interviews, family interviews, and community focus groups in order to explore how their past and present use of personal photography relates to their practices of remembering. ${ }^{2}$ Our recruitment of participants involved snowball sampling from community contacts, circulating a call for participants through community networks and approaching contact names for various social groups, with a premium being put on achieving a balanced composition across gender and generation, and on including participants from various ethnic and social class backgrounds. The intention was not to build a statistically representative sample but instead to select participants from these social groups and categories on the basis of their citation as possible sources of variation in personal media use. The claims we make as a result are not necessarily strong claims; they are nevertheless grounded in the evidence we have accumulated of what people in key social categories say about what they do when they remember through the visual image. The social composition of the sample is detailed in Table One and Two:

Table One. Respondents by age and gender:

\begin{tabular}{|c|c|c|c|}
\hline & Individual Males & Individual Females & $\begin{array}{c}\text { Mixed } \\
\text { couples/groups }\end{array}$ \\
\hline $18-35$ & 10 & 12 & 3 \\
\hline $36-50$ & 3 & 10 & 3 \\
\hline
\end{tabular}




\begin{tabular}{|c|c|c|c|}
\hline $51-65$ & 6 & 4 & 3 \\
\hline 66 and over & 16 & 14 & 4 \\
\hline
\end{tabular}

Table Two. Respondents by broad ethnic group

\begin{tabular}{|l|l|}
\hline White British & 63 \\
\hline White Other European & 21 \\
\hline Black British/African Caribbean/African & 5 (excluding a large group interview) \\
\hline British Asian/Asian & 16 \\
\hline
\end{tabular}

Two further points should be made in relation to our sample. The first is that its overall composition is not reflected in the quotations from interviews chosen for this article as our major criterion for this has been the relevance of what has been said by informants to the points that are being made. For this reason, we only reflect on our informants in terms of the social categories to which they belong where relevant to the analysis. Secondly, we identify our informants mainly by gender, generation and geographical location for two reasons. Firstly gender and generation proved to be much more significant as variables in the analysis than social class or ethnicity. This is not to suggest that these were not important variables in the project more broadly, simply that in relation to the shift from analogue to digital in everyday photography they did not emerge as key points of difference in the experiences and practices of participants. In addition, these categories are often assumed to constitute the major sources of social differentiation in personal media use, with for example generation being cited as crucial to versatility in uses of digital technology. ${ }^{3}$ Contrary to this distinction, we have found men and women across the generations negotiating and utilising new digital technologies, at least so far as those relating to photography are concerned, confounding expectations of a stark generational divide in the use and experience of both analogue and digital photography. We therefore mention particular categories of identification with reference to particular informants in order to demonstrate these commonalities of engagement and use, for although there are definite variations in this respect, commonalities across the categories are equally, if not more notable.

Although the majority of participants took part in one-to-one semi-structured interviews (66 in total), we conducted eleven family interviews and two community focus groups to gather accounts of the sharing of memory along with the shared experience of media technologies. We also used self-interviews and electronic journals (nine and two respectively) in order to provide, for those who desired it, the opportunity to record their memories and remembering practices while on their own. These research methods were linked by their use of the same questioning strategy. The strategy involved photo elicitation methods to facilitate disclosure and draw out people's own accounts and assessments. 
In what follows we focus on changes in key photographic practices that relate to the analogue/digital shift - photo-taking, photo-storing, photo-viewing and photo-sharing - all of which have consequences for the uses of photography as a mnemonic resource. These categories are commonly used in the existing research literature to differentiate between different constituent elements of everyday photographic practice, and in our own research we have found that the practices described by participants fall squarely into these four categories. The categories have all been altered in varying degrees by the advent of digital technologies, but with people continually making comparative evaluations of old and new, drawing on the former as a key aspect of learning how to use the latter. Our interview data shows that at present, across these four categories, vernacular photographic practices manifest a fluid and ambivalent mix of change and continuity, with various adaptations from analogue practice being made alongside accommodations to digital technology. ${ }^{4}$

\section{Photo-Taking}

We begin with the obvious changes resulting from new camera technology and the photo production process associated with it: greater frequency of camera use, larger volume of photographs, higher level of discards, cheaper cost of production. These are evident in the comparison which Helen, a British woman in her forties, makes between her photographic practices as a parent and grandparent:

I didn't take photographs in the way I now take photographs of my grandchildren and that their parents take photographs of them. I mean you could fill entire CDs and photo albums with chil' - er, photographs of my grandchildren, the oldest of whom is five. So in five years an enormous acreage of film has been taken but in my children's childhood I took very few. And I have mixed feelings about this in that I feel almost ashamed that I wouldn't be able to show that I'd been constantly snapping every move and every stage and whatnot of my two children.

Here the analogue/digital shift has led to a retrospective modification in the assessment of Helen's self-image as a parent as she reflects on how the proliferation of images of her grandchildren, providing ample documentation of their development, contrasts with the relative paucity of images she produced of her own children. Her revision sits alongside recognition of her now more finely tuned anticipation of remembering through home-mode photography. ${ }^{5}$ It is not only her feelings that are mixed; so too is the relation of what's new and what endures, for while the number of images taken is much higher, her anticipation of her grandchildren's remembering and her own exhibits a continuation of the performance of family memory that has been integral to popular photography since the introduction of the Kodak camera in the late-nineteenth century.

According to Susan Murray (2008), online photo sharing sites such as Flickr reflect the expansion of photography into everyday life. This does indeed seem to be what is currently happening, yet the incorporation of mundane themes coexists with the older album themes of weddings, holidays and other special occasions. If there is variation in the continuance of this theme, it seems to consist of photos in greater volume taken with a more candid approach, family and friends being captured more in less posed shots and everyday situations. An example of this is the digital photo-taking practice of Lisa, a British woman in her thirties: 
I think with digital cameras you take a lot more photographs because you can be more selective with which ones you want to keep and ... and you can be a bit more informal about it. So you can sort of sit and observe a scene and take 5 or 6 shots and you'll get a different picture every time. You know, people aren't sort of forced to sit there and pose while you wind it on and focus it all up and get the zoom right and everything and then take the photograph and go 'well I'd better just take another one'. You can be more relaxed about it. I think quite often the pictures you get are a lot nicer, because they are more natural and people don't feel - I mean you still do get instances where you get everyone together and smile, but you can sort of take 3 or 4 and people don't notice as much so tend to relax more, forget, look away or laugh or - and I think that is really nice.

Here again we see modification within continuity: firstly, staged and posed shots still occurring, but the increased ease of camera use generating greater candidness and helping to support a narrative of being 'more natural', with people appearing more relaxed and enjoying themselves in the photographer's company; secondly, greater inclusion of the everyday along with the enduring significance of family and leisure as a subject of photography. Both our examples of digital photo-taking show former elements of practice blending with as well as being reoriented by more latter-day elements, in what is an instructive amalgamation of old and new.

\section{Photo-Storing}

Across our interviews respondents expressed anxiety about the possibility of losing personal photographs, with several women who had created family albums claiming they would try to save them, according to a well-worn trope, in the event of 'the house burning down'. Analogue photographs are given particular value, the description of them as 'special' and 'precious' relating primarily to their singular existence, their venerable age and their sustained role in family remembering. In contrast, digital photographs are perceived as more immediate and disposable, due to the ability to see images straight after taking them, in the LCD screen of a digital camera; store and erase them on memory cards; and avoid the cost and time associated with film-processing. They are seen as less unique than their analogue counterparts: the volume of images taken and the ease of reproduction and distribution via the Web tends to diminish the sense of personal possession invested in them. The contrast here is, nevertheless, considerably compromised by our respondents' intense fear of losing their digital images. This reveals not only the interpersonal importance of such images, despite the extra premium put on analogue photographs, but also the extension from the latter to the former in their significance as a mnemonic resource. This can easily remain obscured when it is only the contrast that is spot-lit, with insistence placed on the dichotomous view of analogue and digital photography which we warned against at the outset. Illustratively, 'the house-burning-down' scenario is paralleled by the anxiety manifest in our respondent's digital 'backing up' practices.

Nancy van House (2011) observes that while film photographs once printed are durable, digital photographs are at greater risk because of migration from old to new computers or mistakes occurring in the uses of digital technologies, an example of which 
was recalled by one of our respondents talking of the disappearance of treasured photos. They were gone in an instant: 'I did have a lot of my kids from when they was a baby and that, but somehow the memory card got reformatted so I lost them all' (Craig, a workingclass man in his twenties). The practice of 'backing up' is a response to this, with people managing the risk of loss in various ways by reproducing digital images on memory cards, CDs, online storage facilities, external hard drives and, of course, through printing. Zara, a British woman in her forties, informed us that

I tend to download them onto whatever computer I am at and then put them on disc so I don't lose them ... I must have multiple copies of all of them because I've also got a hard drive, an external drive that I put them on as well. There's a real fear of losing them, a real panic. The ones that are really important to me I print as well. You know, the pictures that have the most significance to me l'll probably go and print.

This is a common response to the distrust of digital technology, and it entails a reversion to analogue practice, not in having multiple copies, since this is made possible by new forms of storage, but in seeing photo prints as a safer form. Printing replicates the materiality of the analogue photo and its more trustworthy status. Although Sutton and Blind (2007: 166) claim that the proliferation of photography online has made it 'essentially object-less', many of our respondents print at least some of their digital images, particularly those considered special, and warranting being displayed and shared. The practice of printing-out brings needed continuity and stability to the digital image that it is seen as not possessing in itself.

A further dimension of the amalgamation of old and new in the analogue/digital shift is the widespread practice of making analogue photographs digital by scanning them and storing them on a PC or uploading them to the internet. Van Dijck (2007) notes the intermediality of photographic practice, arguing that new elements may transform some of the ways we interact with personal items, but intermediality also occurs in the reverse of this, with older elements modifying newer ones, as Glynis (a woman in her seventies) illustrates: 'So we've got hundreds in boxes that need a projector to show them, and I'm slowly working my way through them, choosing the best and putting them on a disc'. The projector and photo-slides are outmoded items of hardware and software, but at the same time the sequential viewing that was characteristic of them is reproduced in newer items as the reformatted images are watched on a PC or TV screen ['see as Slide Show']. In other cases where analogue photographs have been digitised by respondents, all photographs are centralised, coexisting in one place on the PC. In this respect, personal collections give emphasis to the continuation of archiving photographs as family records and conveyances of remembering.

\section{Photo-Viewing}

There is certainly strong evidence that the ways in which personal photographs act as conveyances in this sense is changing. Albeit somewhat speculatively, Nancy Van House puts this evidence in a nutshell when she notes how they 'may be becoming more public and transitory, less private and durable and more effective as objects of communication than of 
memory' (2011: 134; see also Reading, 2008: 359-60).Our own respondents have compared the intimacy of the analogue photograph with its diminution in the digital photograph viewed on screen, with Karen for instance seeing the former as similar in its materiality to a book, while the latter was considered to lack the personal relationship between viewer and image because of its changed reoriented sense of reference:

It's like having something in your hands, whereas on the screen it's always that little bit - errr - non-personal. Erm, what do I want to say? More formal. It's like, well, going to a cinema and seeing it there - it's not really yours (Karen, a British woman in her sixties)

The digital photograph is less proximate, less tangible, less possessable, with the screen altering the effectiveness of the photograph as a vehicle of memory. In the words of Justine, a British woman in her sixties:

I can't sit at my computer and look at photographs and remember the way I can with the album. It doesn't work the same ... They've got to be printed out and put down here'.

If the storage of digital images is not conducive to the structured viewing of the album, with its reassurance of the coherence of life narratively unfolding, we have found many of our respondents making particular efforts to ensure that analogue and digital viewing practices remain coextensive. A key example of this is transforming a selection of their digital photographs into photobooks. The photobook is a printed, case-bound book with personalised images and text. Their creation shows the effort being made to make photo-images proximate, tangible and possessable again, in ways thwarted or deflected by digital photography. They also show continuity with the long-established need to memorialise a holiday, celebration or family occasion:

We've got several hard drives - that's what we need to store the amount of photos that we take. But l'll tend to print books in like series of photos that we want to remember. We try to do one of each year of Edward's life with all of the events that happened, so that hopefully when he gets older he will have a childhood life-history in photos ... And as you flick through them , when you see the proof of the photos it brings the whole event back, whereas when you just see single photos out of context you sort of think 'I remember that part of the day' but forget all the rest (Rhiannon, a British woman in her thirties).

The photobook's style of presenting an implicit narrative in ways closely similar to albums of analogue photographs is held to facilitate future remembering - both Rhiannon's and her child's, once his childhood is over - in ways not felt to be permissible with digital images. In examples such as these, people are compensating for the characteristics of digital photography by revisiting elements of past photographic practice, and they are doing so in order to ensure that photographs retain their previous value as resources of remembering.

This should not be over-generalised, for it is not the case that digital media technologies are universally disqualified as inimical to remembering practices. Some people revere the slideshow screen-saver on a PC, while others relish the screensaver or digital 
photo frame for the ways in which they throw up random images. This randomness is felt to enhance the ability of photo-images to make the absent past present:

Well, I tell you the most ... amazing thing about this is that I look at them more now because l've got a random screensaver system on it ... which is most interesting ...because we, I sort of think, well, that's Italy or that's Rome or whatever, that's, you know, that's in St Petersburg or somewhere or other, so it's a very good way of triggering the memory (Derek, a British man in his seventies).

For some, making the moment of viewing accidental in this way sharpens the attention, refreshes the memory and by combining digital and digitised analogue photos brings the recent and distant past together in ways that do not happen with family albums, photobooks and suchlike collections. Similarly, as a portable and wearable media device, the cameraphone enables personal photographs to be taken with you as you move about in physical space (Gye, 2007; Gumpert and Drucker, 2007). This can modify personal remembering practices, as is made clear by Alma, a woman in her thirties who lives in Croatia:

Now I recently got a little smart-phone and ... I find myself many times a day just you know scrolling through them, yeah, and I have maybe 20 of them, not much, but each one is like 'oh look at this, this is that day, look this is us having coffee'. I don't know why, I am getting more and more with tears, more emotional about events and memory ... Getting more emotions [laughs] like 'oh, I want to remember this'? I don't know, it's something like I appreciate some moments more. Like an ordinary day, coffee with your friend ...

This may be seen in some ways to be quite unlike remembering through the family album because of the viewing of these images 'many times a day' along with the everydayness of some of the scenes depicted, but in others it is not so dissimilar. The images continue to carry a good deal of emotional freight even though they can be viewed more immediately and more regularly. Scrolling through them can still induce intensely private moments, and while mobile phone images can certainly act as objects of communication because of being readily shown and shared, they are no less effective as objects of memory. In addition, as we have seen, particular digital technologies are used significantly in relation to photographic remembering, the screensaver and camera phone having qualities that lend themselves to private remembering.

\section{Photo-Sharing}

Private remembering is clearly not effaced in the use of digital technologies even though they have facilitated different, and more public uses of photography as a mnemonic resource. This is also the case with how photos are shared. With the family album, sharing takes place in intimate, focused gatherings, and this highly localised form of interaction through images now continues alongside the far more dispersed forms of exchange that occur through photographs being sent as email attachments, as adjuncts to text messages, or as postings on online networking sites. Sharing is clearly intended in posting to photo- 
sharing sites, though of course these activities emphasise display and do not have to be accompanied by dialogue or annotation. It may seem that this diminishes the role of personal photography in the construction of personal and group memory, yet the great majority of our respondents have insisted that in distributing photos via social networks and photo-sharing sites, they feel that they are sharing with a connected rather than anonymous audience. For example, Joan, a British woman in her sixties, discussed sharing photographs on Facebook of the school that both she and her daughter had attended as pupils:

There was a different head teacher there and they had,er - it's an independent girl's school ... She [her daughter] and her friends were asked to go to the head teacher's office after the rehearsal and she said 'we wondered what awful crime we'd committed', and apparently they were fiddling with their red ribbons. That was what the problem was.So when I put it up on Facebook and I - there are a number of old girls - former and erm, modern day ones on Facebook - so I just put 'guess', you know, 'guess where I was last night? And not a red ribbon in sight'.

By posting the photograph with comments onto Facebook, Joan communicated her connection to a past shared with other former pupils, a directly intended set of recipients whom she felt would appreciate the comparative assessment of cross-generational experience of the school which she made through her daughter's 'red ribbons' story.

Similarly, both the immigrants and international students we interviewed emphasised how posting photographs on social networks helps them remain connected with family and friends 'back home'. Online practices such as 'tagging' photographs instigated communication in the absence of communication:

But lately Facebook has...it works very nicely because I was doing some trips with students here, international students, and they were taking photos, they put them on Facebook and they were tagging me in their photos too. And my friends in Romania saw me in those photos. So I didn't need to do anything [laughs] so some people did all the mediation: they were taking the photos, tagging me and the other people, my friends from Romania, saw them directly from because I was tagged [laughs] so I'm 'ok this is good, I don't need to write to them to tell them where I've been last weekend' because they have already seen the photo and the name of the place (Veronica, a Romanian woman in her twenties).

For some, practices such as this may cause a sense of disquiet or irritation, and in a similar way to the selectivity involved in deciding with whom to share the contents of a family album, most of our respondents feel the need for caution and care in posting photos onto sites like Facebook. For example, Pramsu, a young man from India, talked in a self-interview of Facebook 'functioning like an album', and as with an album of the need to be 'very careful of the images that I'm putting out there ... I'm not putting out images that I don't want to share with particular people'. Another respondent, a British woman in her 40s, told us:

I'm very selective about what I put on Facebook. I mean mine are only available to friends anyway. I made it that, I don't know whether it's a mistake or not because when I first put them on Facebook, you know, everybody makes the catalogue of 
mistakes when you first go on Facebook, letting everybody see all of your personal details and everything. You soon learn. And this girl emailed me from Australia and she had seen my dress on my wedding photos and she was very polite, she was lovely, there was nothing wrong with it. In some respects it was really nice because it got us into this email conversation about weddings, Australia and all sorts, but she'd seen it on my...how on earth had she came across me? (Rachel).

There are, then, strong concerns about ensuring specific online linkages and in not allowing personal images to spread indiscriminately, which is why the privacy settings on social network sites are important to everyone we have interviewed. In the use of such sites, attempts are regularly made to ensure that intended lines of communication are neither broadened nor blurred against the will of the sender/compiler. This parallels the control over albums even though it is exercised in different ways and not always with sure knowledge of success. Control has clear implications not only for what is remembered via photo-images, but by whom photo-remembering is shared. In research on cameraphone use conducted by Anna Reading in London during April and May 2006, it was found that this now ubiquitous device, 'situated at the interstices of the public and private', was being adopted by women 'more like a portable "family album"', rather than in an attempt to realise its potential as 'a globally networked memory prosthetic'; for the women she interviewed its primary use was 'to deepen established relationships rather than extend memories into a wider circle' (Reading, 2008: 361). This relates closely to the contextual need to know the people captured in photo-images for such images to have any marked degree of personal meaning or value. Our own respondents are strongly aware that when they post photographs online - whether digitised analogue or digital photographs - they have a distributed presence that extends way beyond the images in an album, but several of them made clear that when they do go beyond the family or friends for whom they are usually intended, they have little if any meaning as memory-conveyances, and cannot be used in the same way that a personally shared image acts as form of remembering between intimates.

Photo-sharing practices have clearly changed from twenty years or so ago, but the continuities that are involved, even when they evince modifications from what earlier prevailed, are easily obscured when emphasis falls on short-term change. Sharing images sometimes occurs in quite new ways, sometimes in older ways or ways which mimic older ways, as with the photobook. Sharing is of course preliminary to, or a common part of, remembering. Although various studies of photo-sharing websites have argued that they represent a movement away from the uses of photography in remembering, Palmer's study of the archiving of emotion in online photo sharing on the biography site 'thisMoment' demonstrates its use as a platform for promoting photographic remembering practice. The site'thisMoment' is shown to encourage the packaging of the user's life as a succession of dramatic moments through a timeline of photographs (Palmer, 2010: 121). Similarly, Van Dijck's research on Flickr shows that photo-sharing sites 'actively construct connections between perspectives, experiences and memories' (2011: 402). The distribution of digital photographs to larger, more dispersed audiences does not necessarily lessen photography's function as a memory tool. It may even be augmenting it through the proliferation of images generated by digital and mobile phone cameras. 
The move from 'Kodak culture' to 'Snaprs culture', as Christophe Prieur et.al. (2008) have it, is not one of complete disseverance. The move may seem that way when attention focuses exclusively on technological development, but the picture becomes more complex once we take a methodological turn towards practice. Taking this turn enables to see, inter alia, that the shift to digital cameras and cameraphones does not necessarily militate against the conventional practice of sharing memories and stories of our lives around personal photographs, as Lisa Gye has claimed. While she acknowledges that new camera technologies 'reinforce and extend existing photographic practices' as well as creating new practices, she argues that they work against 'the enabling techniques' of shared conversations and storytelling through which personal photographs operate as mnemonic resources (Gye, 2007: 282-3). It is true that online photo-sharing may not involve dialogue and interaction, virtual or otherwise, but often these take other forms - texting, emailing, networking - or serve as a plank for conversation or reminiscing when online sender and recipient next meet in the flesh. In addition, the uses of albums in remembering practices have not simply disappeared as a result of new forms of image-making, storing, viewing and sharing. People are continuing to operate, or finding new ways of adapting, the mnemonic framework that is constructed out of photo compilations. New technologies have brought new opportunities, and certain aspects of photographic practice have changed as they have been taken up, as we have seen for example with Alma's use of smart-phone images, but it is not as if practice falls smartly into line behind every new step in technological development. A major reason for this, underlying so much of what was said in our interviews, is the continued importance of creating coherent narratives out of the unruly welter of experience, and utilising the mnemonic affordances of personal photography in doing so.

Indeed, the personalised uses of digital technologies remain in many ways centred around a continuing search for narrative meaning in the succession of images from the past which people accumulate and arrange in one way or another. This is a clear extension from the ways in which albums have been used throughout the previous century. As we have seen, digital images are obviously stored and shared in different ways, but this does not mean the family album is necessarily doomed. Storage and display are taking different forms alongside the album, while older forms like the album are being recreated in the photobook and (to some extent) on social network sites. Personal albums in the past may have concentrated on the special occasion, while the proliferation of images made possible by the digital camera is now leading to 'the public display of everyday situations that construct the self' (Richter and Schadler, 2009: 176; see also Rubinstein, 2005: 117, and Murray, 2008), but special occasions and everyday situations are not mutually exclusive. There is clear evidence that - to some extent at least - cameraphones are being used to create short-lived images of mundane events, while digital cameras are the device of choice for recording and hence remembering special occasions, such as landmark birthdays, weddings or Bar Mitzvahs. Images of these are being compiled into photobooks, at least by some of our respondents. So while new options for self-representation and self-narration are opening up, they extend from the abiding need to find narrative meaning and significance across the different stages and periods in one's life. 


\section{Conclusion}

For much of its history, popular analogue photography was aesthetically derided and regarded by scholars as of little social, cultural or historical value. That has gradually changed, and some important academic studies of such photography have appeared, though these remain far outweighed by the number of studies of art photography and photographic artists. Our own work is predicated on the belief that researching vernacular photography can tell us much about how people socially orient themselves and develop a range of evaluative perspectives on various dimensions of their everyday lives. Contrary to previous assumptions and claims, often developed critically de haut en bas, it provides strong evidence that those who take, store, view and share in vernacular photography are not simply unwitting accomplices in the reproduction of an ideological status quo. What they do and say can tell us much about the self-reflexivity inherent in their photographic practices. This should be readily apparent even in the few extracts we have taken from the interviews we have conducted in investigating the uses of photography as vehicles of memory. These uses are changing as people accommodate themselves to the various key items of digital technology involved across the four categories associated with popular photography, but the changes are not wholesale, as we have tried to make clear.

The personal and intra-group use of digitalphoto-images shows no straightforward before/after scenarios but a continual interweaving of established and emergent practices. This is strongly influenced by the need - sometimes imperatively felt - to maintain a longerterm pattern across vibrant strands of remembering while also taking advantage of new opportunities. In the always ongoing, mutual interaction of established and emergent practices, moments of historical change are not starkly identifiable in any temporally singular or isolated manner, and do not suddenly become manifest because of the widespread take-up of some newly marketed item of technology like the digital camera. This brings us back to the rhetoric involved in the techno-centric dichotomy set up between analogue and digital photography with its self-affirming emphasis on change. Both academic and journalistic writing on new media are prone to the danger of exaggerating such change. In an argument similar to ours, Paul Cobley and Nick Haeffner have pointed up this danger in noting that 'any investigation of a specific and new medium ... tends to identify novel features in relation to other media and, often, to imagine that those features are immutable characteristics of the medium' (2009: 141). Countering the technological essentialism involved in this, they cite Horst and Miller's (2006) anthropology of the mobile phone in Jamaica. Early on in that study they observe that in the literature on telephony, 'texts that consider the widest possible context for understanding the usages and consequences of the telephone [are] much more effective than those that start too narrowly from a supposed intrinsic quality of the technology itself' (2006: 166). This is closely in line with the position we have been taking in this article, for it is vital that we start not with the media technology itself but with how everyday cultural negotiations, accommodations, adaptations and extensions from older practices are managed and reflexively considered.

Throughout this article we have attempted to develop an approach based on this methodological premise, avoiding the temptations of techno-centrism by focusing instead on the interplay between convention and practice, innovation and emergence. As we do this, 
we see that the transformative potential of digital camera technologies is not necessarily as wide-reaching as has been claimed. Indeed, we soon discern that reports of the death of photography have been greatly exaggerated. Claims of its demise have arisen primarily in commentary on professional photography, and been centred on anxieties that the consequence of the manipulative capabilities of digital technologies would cause photographs to 'lose their value as social records and representations of reality' (Tysome, 1993: 48). These are understandable anxieties, and they have been felt in various ways by anyone concerned with the politics of representation, whether in advertising, photojournalism, documentary reportage or any other form of pictorial media. Instructively, worries about the manipulation of images have not been expressed by any of our respondents. Vernacular photography is a field where philosophical concern over the ontology of the image carries little weight. This finding is paralleled in an interlocking group of studies of everyday photography conducted over several years in the United States by Nancy van House and her co-researchers. They have found that 'the popular view remains that photographs "capture the moment"' and images are seen 'as memories made durable, correctives to fallible human memory' (Van House, 2011: 130).Details such as this, which seem quite specific to vernacular photography, would have emerged earlier if different genres and categories of photographic practice had not been elided, and empirical study, rather than speculative theorising, had been at the forefront of scholarly activity following the advent of digital photography. ${ }^{6}$ With ground-level vernacular use, digital photography has raised different concerns, such as ensuring at least a degree of cross-temporal continuity in the take-up of new means of making visual records, and integrating innovative techniques and capabilities into the everyday cultural worlds represented in both analogue and digital images, along with all the affective investments that people make in their homemode products.

With vernacular photography, technological change is in tension with earlier social and cultural practices and rituals, and at present what is most clearly observable is the awkward coexistence of different modes and uses, purposes and practices, in varying configurations. For this reason, José van Dijck (2008: 59-60) is entirely justified in saying that 'personal photography has not changed as a result of digital technologies; the changing function of photography is part of a complex technological, social and cultural transformation'. That is a view with which we very much concur. In attending to this changing function in everyday life, and especially in its relations with memory and processes of remembering, we need to understand the ways in whichdigital images are being used as continuous with analogue practice, rather than being assumed as radically separate from it. Continuities of practice and convention are, of course, operating under changed conditions, as for example with the shifting boundaries between public and private, and the less predetermined processes of image production and reproduction, yet so far as vernacular photography is concerned, we need nevertheless to understand change against continuity, and continuity against change, with both gaining or retaining their significance through their mutual interaction. 


\section{References}

Allett, N, Keightley. E. and Pickering, M.,'Using Self-Interviews to Research Memory', Realities at the Morgan Centre, available athttp://www.manchester.ac.uk/morgancentre/realities/toolkits/

Bowker, G. (2005) Memory Practices in the Sciences, Cambridge, MA: MIT Press.

Chalfen, R. (1987) Snapshot Versions of Life, Bowling Green, OH: Bowling Green State University Press.

Cobley, P. and Haeffner, N. (2009) 'Digital Cameras and Domestic Photography: Communication, Agency and Structure', Visual Communication, 8:2, pp.123-46.

Crary, J. (1993) Techniques of the Observer, Cambridge, MA: MIT Press.

Gumpert, G., and Drucker, S. (2007) 'Mobile Communication in the $21^{\text {st }}$ Century or "Everybody, Everywhere, at Any Time" in Kleinman, S. ed. Displacing Place, New York: Peter Lang, pp. 7-20.

Gye, L. (2007) 'Picture This: The Impact of Mobile Camera Phones on Personal Photographic Practices', Continuum: Journal of Media and Cultural Studies, 21: 2, pp. 279-88.

Horst, H. and Miller, D. (2006) The Cell Phone: An Anthropology of Communication, Oxford: Berg.

Keightley, E., Pickering, M., and Allett, N. (2012) 'The Self-interview: A New Method in Social Science Research'. International Journal for Social Research Methodology http://www.tandfonline.com/doi/abs/10.1080/13645579.2011.632155

Lee, D.H.(2010) 'Digital Cameras, Personal Photography and the Reconfiguration of Special Experiments', Information Society, 26: 4, pp. 266-275.

Mitchell, W. (1994) The Reconfigured Eye: Visual Truth in the Post-photographic Era, MIT Press

Murray, S. (2008) 'Digital images, Photo-sharing, and Our Shifting Notions of Everyday Aesthetics',Journal of Visual Culture, 7:2, pp. 147-163.

Palmer, D. (2010) 'Emotional Archives: Online Photo Sharing and the Cultivation of Self', Photographies, 3:2, pp. 155-171.

Pickering, M. and Keightley, E. (2013) 'Vernacular Remembering' in Keightley,E. and Pickering, M. eds. Research Methods for Memory Studies, Edinburgh: Edinburgh University Press.

Prensky, M. (2001) 'Digital Natives, Digital Immigrants', On the Horizon, 9:5, pp. 1-6. 
Prieur, C., Cardon, D., Beuscart, J.S., Pissard, N., and Pons, P. (2008) 'The Strength of Weak Cooperation: A Case Study of Flikr', available at http://arxiv.org/abs/0802.2317

Reading, A. (2008) 'The Mobile Family Gallery? Gender, Memory and the Cameraphone', Trames, 12: 3, pp. 355-65.

Richter, R. and Schadler, C. (2009) 'See My Virtual Self: Dissemination as a Characteristic of Digital Photography - The Example of Flickr.com', Visual Studies, 24:2, pp. 169-77.

Ritchin, F. (1990) 'Photojournalism in the Age of Computers' in C. Squiers, ed. The Critical Image, Seattle: Bay Press, pp. 28-37.

Rubenstein, D. (2005) 'Cameraphone Photography: The Death of the Camera and the Arrival of Visible Speech',Issues in Contemporary Culture and Aesthetics, 1, pp. 113-18.

Sarvas, R. and Frohlich, D. M. (2011) From Snapshots to Social Media - The Changing Picture of Domestic Photography. London: Springer.

Sutton, D. and Blind, S. (2007) The State of the Real: Aesthetics in the Digital Age, London: I.B. Tauris.

Trachtenberg, A. (2008) 'Through a Glass, Darkly: Photography and Cultural Memory', Social Research, 75: 1, pp. 111-32.

Tysome, T. (1993) 'Light and Dark', The Times Higher, 14 May,p. 48.

Van Dijck, J. (2007) Mediated Memories in the Digital Age, Stanford, Cal.,: Stanford University Press.

Van Dijck, J. (2008) 'Digital Photography: Communication, Identity, Memory', Visual Communication, 7:1, pp. 57-76.

Van Dijck, J. (2011) 'Flikr and the Culture of Connectivity: Sharing views, Experiences, Memories', Memory Studies, 4 :4,pp. 401-415.

Van House, N.A. (2011) 'Personal Photography, Digital Technologies and the Uses of the Visual', Visual Studies, 26:2, pp. 125-134.

\footnotetext{
${ }^{1}$ The data is associated with a research project, funded by the Leverhulme Trust(F/00 261/AC), which investigates the uses of media technologies in everyday life and the ways in which these relate to practices of remembering.

${ }^{2}$ On self-interviews, see Allett, Keightley and Pickering, 2011; Keightley, Pickering and Allett, 2012; and Pickering and Keightley, 2013.

${ }^{3}$ See for example Prensky (2001) on the distinction between 'digital natives' and 'digital immigrants'.

${ }^{4}$ There is clearly a wider debate to be had about the ways in which the gender, class, and ethnic politics of everyday remembering are transformed or re-articulated in the complex oscillations between analogue and digital photographic practice. While the relationships of power articulated in and performed through digital and analogue photographic practices can be observed in our data, investigating these relationships is not our primary concern in this article and has not motivated the illustrative empirical examples that we present. An explicitly political analysis cannot be undertaken until there has been an assessment of the domains of photographic activity in which technological transition is experienced and articulated in practice. That is what we attempt here.
} 
${ }^{5}$ The term 'home mode' was coined by Richard Chalfen (1987) in a pioneering study of domestic uses of photography and filmmaking.

${ }^{6}$ According to Van House (2011: 133), across a five-year period none of their participants 'expressed any interest or concern about the potential falsification of images'. Pickering and Keightley (2013) call for more ethnographically-based research into home-mode media as well as surveying the methods and methodological issues involved in studying such media and their relationship to practices of remembering. 